\title{
OS ROYALTIES DE ITAIPU NA EDUCAÇÃO: UMA ANÁLISE NOS MUNICÍPIOS LINDEIROS NO OESTE DO PARANÁ
} (1985-2016)

\author{
LOS ROYALTIES DE ITAIPÚ EN LA EDUCACIÓN: UN ANÁLISIS EN \\ LOS MUNICIPIOS LINDEIRES DEL OESTE DE PARANÁ (1985-2016)
}

THE ROYALTIES OF ITAIPU IN EDUCATION: AN ANALYSIS IN THE LINDEIRES MUNICIPALITIES IN THE WEST OF PARANÁ (1985-2016)

DOI: $10.22481 / \mathrm{rbba} . v 10 \mathrm{i} 01.8822$

João Carlos da Silva

Universidade Estadual do Oeste do Paraná, Paraná, Brasil

ID Lattes: http://lattes.cnpq.br/0234527171754099

ORCID: https://orcid.org/0000-0002-9322-8754

Endereço eletrônico: Joao.Silva@ unioeste.br

Juliana Schwaab Thibes Universidade Estadual do Oeste do Paraná, Paraná, Brasil

ID Lattes: http://lattes.cnpq.br/4515078712345172

ID Lattes: https://orcid.org/0000-0002-5534-835X

Endereço eletrônico: juschwaab@hotmail.com

\section{RESUMO}

O presente artigo tem como objetivo discutir a aplicabilidade dos royalties repassados pela Hidrelétrica Binacional de Itaipu, observando seus impactos no campo educacional. A assinatura do Tratado de Itaipu, em 1973, ocorreu mediante tensões políticas a partir dos interesses geopolíticos, no contexto da Guerra Fria em face do modelo nacional-desenvolvimentista em plena Ditadura Civil-Militar (1964-1985). A construção da usina produziu mudanças significativas no cenário econômico, social e territorial 
nos municípios lindeiros ao lago de Itaipu. Grande parte da população que vivia em áreas rurais foi evacuada, deixando terras produtivas submersas a uma grande quantidade de água, para assim, dar lugar ao projeto da construção da maior hidrelétrica do mundo da época. A formação do reservatório inundou uma grande área dos municípios ao lago de Itaipu, estando Santa Helena e Itaipulândia entre os maiores atingidos, vindo a perder uma grande parte de suas áreas produtivas, sendo, portanto, os maiores recebedores das parcelas dos royalties, conforme previsto na Constituição Federal de 1988, em seu Art. 20. A partir de pesquisa bibliográfica e documental, procuramos fazer uma análise dos investimentos realizados na educação nesses municípios. Os repasses efetuados criaram possibilidades, expectativas e perspectivas de ampliação e melhorias das escolas públicas na região oeste do Paraná.

Palavras-Chave: Itaipu; Royalties; Investimentos; Educação Básica.

\section{RESUMEN}

Este artículo tiene como objetivo discutir la aplicabilidad de los royalties transferidos por la Central Hidroeléctrica Binacional Itaipú, observando sus impactos en el ámbito educativo. La firma del Tratado de Itaipú, en 1973, se produjo a través de tensiones políticas basadas en intereses geopolíticos, en el contexto de la Guerra Fría frente al modelo nacional-desarrollista durante la Dictadura Civil-Militar (1964-1985). La construcción de la central hidroeléctrica Binacional Itaipu produjo cambios significativos en el escenario económico, social y territorial de los municipios aledaños al lago de Itaipu. Gran parte de la población que habitaba en zonas rurales fue evacuada, dejando las tierras productivas sumergidas en una gran cantidad de agua, para dar paso al proyecto de construcción de la mayor central hidroeléctrica del mundo en ese momento. La formación del embalse inundó gran parte de los municipios denominados lindeiros al lago de Itaipu, siendo Santa Helena e Itaipulândia los más afectados, habiendo perdido gran parte de sus áreas productivas, siendo, por tanto, los mayores receptores. de las cuotas de royalties según lo previsto en la Constitución Federal de 1988, en su Art. 20. Con base en la investigación bibliográfica y documental, buscamos hacer un análisis de las inversiones realizadas en educación en estos municipios. Las transferencias realizadas crearon posibilidades, expectativas y perspectivas para la expansión y mejoramiento de las escuelas públicas en la región occidental de Paraná.

Palabras clave: Itaipu; Royalties; Inversiones; Educación básica. 


\begin{abstract}
This article aims to discuss the applicability of royalties transferred by the Itaipu Binational Hydroelectric Power Plant, observing its impacts in the educational field. The signing of the Itaipu Treaty, in 1973, occurred through political tensions based on geopolitical interests, in the context of the Cold War in the face of the national-developmentalist model during the Civil-Military Dictatorship (1964-1985). The construction of the Binacional Itaipu hydroelectric plant produced significant changes in the economic, social and territorial scenario in the municipalities bordering the lake of Itaipu. A large part of the population that lived in rural areas was evacuated, leaving productive lands submerged in a large amount of water, in order to give way to the project for the construction of the largest hydroelectric plant in the world at the time. The formation of the reservoir flooded a large area of the municipalities called lindeiros to the lake of Itaipu, with Santa Helena and Itaipulândia being among the hardest hit, having lost a large part of their productive areas, being, therefore, the biggest recipients of the royalties installments, as foreseen in the Federal Constitution of 1988, in its Art. 20. Based on bibliographic and documentary research, we seek to make an analysis of the investments made in education in these municipalities. The transfers made created possibilities, expectations and perspectives for the expansion and improvement of public schools in the western region of Paraná.
\end{abstract}

Keywords: Itaipu; Royalties; Investments; Basic education.

\title{
INTRODUÇÃO
}

A trajetória histórica da construção de Itaipu, considerada a maior geradora de energia limpa e renovável do planeta, localizada na região oeste do Paraná, a partir de 1974, em plena ditadura civil-militar (1964-1985), ficou marcada por um rastro de acontecimentos e muitas controversas, envolvendo disputas geopolíticas, expansão do capitalismo e prioridade nas ações governamentais para abastecer a energia das indústrias, especialmente na região sudeste do país. Tal iniciativa produziu financiamentos externos, impactos ambientais irreversíveis, onde milhares de agricultores tiveram que abandonar suas propriedades produtivas, em nome do "progresso".

O oeste paranaense passou por intensas transformações de cunho socioeconômico e geográfico, proporcionado pela formação do maior lago artificial do mundo, em 1982. Os quinze municípios do Estado do Paraná e 01 do Mato Grosso do Sul que tiveram suas terras 
atingidas. Com finalidade de amenizar os impactos causados na região oeste, Itaipu criou programas que vem desenvolvendo ao longo dos anos, com intenção de preservar o meio ambiente e fomentar a economia na região.

Entendendo que a educação é considerada um dos principais fatores de desenvolvimento de um país, nos remete a pensar quanto maior e melhor forem os investimentos nesta área, melhores serão os resultados. É nesta perspectiva que nossa análise será conduzida, com intensão de verificar quais investimentos foram realizados por estes gestores na educação básica, delimitando nossa discussão em Santa Helena e Itaipulândia, por serem os municípios com maior recebimento de royalties. Nesta perspectiva, discutimos os repasses financeiros efetuados pela usina de Itaipu, o que em tese permitiram novas possibilidades e perspectivas de ampliação e melhorias para as escolas públicas na região oeste do Paraná.

A construção da usina hidrelétrica Binacional de Itaipu, produziu mudanças significativas no cenário econômico, social e territorial nos municípios lindeiros ao lago de Itaipu. Grande parte da população que vivia em áreas rurais foi evacuada, deixando terras produtivas submersas a uma grande quantidade de água, para assim, dar lugar ao projeto da construção da maior hidrelétrica do mundo da época. Após ter ocorrido o alagamento e a usina de Itaipu iniciar sua comercialização de energia em 1985, os municípios passaram a receber os royalties mensalmente, conforme previsto na Constituição Federal de 1988. Desta forma, o presente artigo examina a aplicabilidade desses recursos na educação pelos municípios lindeiros ao lago de Itaipu, observando seus aspectos quantitativos e qualitativos no campo educacional.

Este artigo está dividido em dois momentos que se relacionam: no primeiro pontua os aspectos histórico-políticos que envolveram a construção de Itaipu. No segundo, apresenta os dados dos recursos dos royalties dos municípios integrantes e seus efeitos na melhoria da educação.

\section{OS ROYALTIES E A EDUCAÇÃO}

No Brasil, os royalties são pagos por várias explorações de fontes naturais, tanto não renováveis, como é o caso do petróleo, minerais, gás natural, biocombustível como também renováveis, como a exploração do aproveitamento hídrico. Os royalties pagos pelas usinas hidrelétricas são Compensações Financeiras pelo Uso de Recursos Hídricos (CFURH), pagos 
aos municípios e Estado, pelo aproveitamento de águas de rios para a geração de energia elétrica. Trata-se de um ressarcimento aos municípios que tiveram perdas territoriais por meio da inundação de áreas para a formação de reservatórios.

A Constituição Federal de 1988, em seu Artigo 20 , define como um dos bens da União os potenciais de energia hidráulica e garante compensação financeira aos Estados, Distrito Federal, Municípios e Órgãos da União em caso de exploração de recursos hídricos para a geração de energia elétrica. As pequenas usinas hidrelétricas, ou Pequenas Centrais Hidrelétricas (PCHs), com potência equivalente a $10 \mathrm{MW}$ até $30 \mathrm{MW}$, foram isentas do pagamento dos royalties, conforme previsto na Lei $\mathrm{n}^{\circ} 7990 / 89$ e mais tarde alterada pela Lei $\mathrm{n}^{\circ}$ 9648/98.

As construções de grandes usinas hidrelétricas, apesar de gerarem uma energia limpa e renovável, causam impactos severos ao meio ambiente e às cidades, como, por exemplo, as inundações de florestas e terras férteis, alteração ou desaparecimento do habitat de animais e alterações econômicas nos municípios atingidos, justificando o pagamento pela compensação financeira.

Na década de 1970, em face das demandas da produção capitalista, o Brasil ingressou em uma fase de crescimento industrial, fazendo suas máquinas operarem a todo o "vapor", efetivando monopólio industrial. No mesmo período, outro fator que colaborou para o crescimento industrial no Brasil e Argentina foi o bloqueio do Oceano Atlântico, resultado das duas grandes guerras mundiais, que impossibilitava a importação de manufaturados, alterando a dominação que até então era apenas colonial.

O desejo do desenvolvimento expresso pelo governo militar implicou grandes obras que ficaram conhecidas como "faraônicas", característica dada pela grandeza e magnitude das obras, sendo consideradas as principais: Usinas de Itaipu, Tucuruí e Tubarão; Estrada de ferro de Carajás; Programa Nuclear - Angra 1, 2 e 3; Metrôs do Rio de Janeiro e São Paulo; Ponte Rio-Niterói; Rodovia Transamazônica entre outras obras, despertando interesses de muitos bancos internacionais.

A fase de industrialização e a crise do petróleo ${ }^{i}$, instaurada mundialmente, gerariam um colapso na produção de energia elétrica que em pouco tempo não seria mais suficiente para abastecer as grandes cidades industriais e um racionamento de energia levaria ao descontentamento dos industriais. Conforme dados de Xavier, Ribeiro e Noronha (1994), o barril do petróleo que custava 3 dólares no ano de 1973, passou para 12 dólares no ano seguinte. 
Concomitantemente, o rápido crescimento industrial brasileiro, além das máquinas operando, demandava cada dia mais produção e elevava o consumo elétrico. O setor energético em pouco tempo não teria mais capacidade suficiente para abastecer as grandes cidades industriais:

Os argumentos utilizados para justificar o projeto estavam apoiados nos ideais dos militares de tornar o Brasil uma grande potência. E, para o desenvolvimento do país, era necessário produzir energia elétrica. Dentro deste contexto, em 1974 foi criada a entidade Itaipu Binacional e no ano seguinte foi dado início às obras (MASCARENHAS; CASTANHA, 2010, p. 80).

O milagre econômico, no governo militar, de um lado, resultou em um crescimento econômico, de outro, baixo valor do salário mínimo, que vinha reduzindo anualmente, podendo ser comparado ao valor correspondente ao ano de 1944. Os militares apresentavam como principais metas o desenvolvimentismo a partir do crescimento industrial, com o lema "Brasil potência".

Esse ideário levou os militares a realizarem grandes investimentos, principalmente na área de infraestruturas para favorecer a industrialização. Desta forma, a produção elétrica tornase alvo primordial para abastecer as fábricas, elevando a necessidade do governo em construir usinas hidrelétricas, julgadas mais apropriadas pelas condições naturais que o Brasil apresentava, e a Itaipu surge neste contexto.

O termo royalties, plural da palavra royalty em inglês, designa regalia ou privilégio, consistindo em uma quantia paga por alguém ao proprietário pelo direito de usar, explorar ou comercializar um produto, obra ou terreno. Em nosso país os royalties são pagos por várias explorações de fontes naturais como é o caso do petróleo, minerais e potenciais de energia hidráulica.

A Constituição Federal de 1988, em seu Artigo 20, define como um dos bens da União, os potenciais de energia hidráulica e garante compensação financeira aos Estados, Distrito Federal, Municípios e Órgãos da União em caso de exploração de recursos hídricos para a geração de energia elétrica.

O Decreto Federal no 1 de 11 de janeiro de 1991 estabelecia a compensação financeira pela utilização dos recursos hídricos o cálculo e a distribuição mensal decorrentes ao aproveitamento dos recursos hídricos, para a geração de energia elétrica, bem como os royalties devidos pela Itaipu Binacional ao Governo Brasileiro, pelo Tratado de Itaipu. 
A Lei $\mathrm{n}^{\circ} 8.001 / 90$, recentemente alterada pela Lei $\mathrm{n}^{\circ} 13.661$ de 8 de maio de 2018, prevê a distribuição mensal dos royalties, estabelecendo o pagamento de 25\% aos Estados; 65\% aos municípios; $3 \%$ ao Ministério do Meio Ambiente; 3\% ao Ministério de Minas e Energia; 4\% ao Fundo Nacional de Desenvolvimento Científico e Tecnológico.

Com a legislação dos royalties e a comercialização da energia elétrica produzida pela Usina de Itaipu, iniciou-se o repasse mensal beneficiando 15 municípios do Estado do Paraná e 01 do Estado do Mato Grosso do Sul que foram afetados pelo alagamento, sendo o valor proporcional a quantidade de área alagada.

A tabela a seguir demonstra os 16 municípios beneficiários dos royalties, seguido pelo montante recebido no mês de janeiro de 2017 e a quantidade de área submersa pelo lago, conforme publicação da Aneel. Podemos observar que os municípios mais beneficiados com os royalties são: Santa Helena, Foz do Iguaçu e Itaipulândia.

Tabela 1 - Indicação dos Municípios, áreas alagadas

\begin{tabular}{|l|l|}
\hline Município & Área alagada $\mathbf{k m}^{\mathbf{2}}$ \\
\hline Foz do Iguaçu & 201,84 \\
\hline Santa Terezinha de Itaipu & 41,90 \\
\hline São Miguel do Iguaçu & 90,91 \\
\hline Itaipulândia & 179,73 \\
\hline Medianeira & 1,16 \\
\hline Missal & 40,07 \\
\hline Santa Helena & 263,76 \\
\hline Diamante do Oeste & 5,62 \\
\hline São José das Palmeiras & 1,94 \\
\hline Marechal Cândido Rondon & 56,04 \\
\hline Mercedes & 19,32 \\
\hline Pato Bragado & 47,07 \\
\hline Entre Rios do Oeste & 32,90 \\
\hline Terra Roxa & 1,58 \\
\hline Guaíra & 51,01 \\
\hline Mundo Novo (MS) & 14,71 \\
\hline
\end{tabular}

Fonte: Aneel (2007).

O crescimento industrial brasileiro estava em alto nível de desenvolvimento e a necessidade de fazer suas máquinas produzirem, levou o consumo elétrico à beira de uma crise energética, pois a energia já em crise, em pouco tempo não seria mais suficiente para abastecer as grandes cidades industriais: 
Os argumentos utilizados para justificar o projeto estavam apoiados nas ideias dos militares de tornar o Brasil uma grande potência. E, para o desenvolvimento do país, era necessário produzir energia elétrica. Dentro deste contexto, em 1974 foi criada a entidade Itaipu Binacional e no ano seguinte foi dado início às obras (MASCARENHAS; CASTANHA, 2010 p.80).

O Rio Paraná, em seu grande volume de água, seria o ideal para a construção de uma usina hidrelétrica, porém havia a divisão entre Brasil, Paraguai e Argentina, o qual o Rio percorria que poderia tornar-se um empecilho, sendo a vontade dos idealizadores que a usina pertencesse somente ao Brasil, não havendo assim, a necessidade de divisão com os outros países.

Conforme Mazzarollo (2003), depois de estudos técnicos, realizou-se em 1966, na cidade de Foz do Iguaçu um acordo diplomático entre Brasil e Paraguai, sendo assinada a Ata do Iguaçu, como demonstração de interesse em aproveitar esse potencial energético.

Em abril de 1973, Brasil e Paraguai assinaram o acordo, que ficou conhecido como "Tratado de Itaipu", com a finalidade de usufruírem os recursos hídricos do rio Paraná, que tinha como percurso o Salto de Sete Quedas até a Foz do Rio Iguaçu. Foi necessário inundar uma área com cerca de $1.400 \mathrm{~km}^{2}$, sendo $800 \mathrm{~km}^{2}$ do lado brasileiro e $600 \mathrm{~km}^{2}$ do lado paraguaio. Em 1974, com a chegada das primeiras máquinas iniciou-se a construção da maior usina hidrelétrica do mundo.

Foz do Iguaçu, que possuía cerca de 20 mil habitantes e apenas duas ruas asfaltadas passou por uma transformação drástica e em 10 anos a população saltou para mais de 100 mil habitantes. Entre os anos de 1975 e 1978 foram construídas mais de 9 mil casas dos dois lados dos países para acomodar os trabalhadores que vieram de toda a parte do Brasil, sendo ainda construído hospitais, escolas, igrejas, clubes e centros esportivos para melhor atendê-los.

A primeira tarefa que os operários tinham era alterar o curso do rio, sendo necessário escavar $2 \mathrm{~km}$ de extensão, 150 metros de largura e 90 metros de profundidade para fazer o desvio, onde seria construída a barragem em concreto. Este trabalho terminou em 20 de outubro de 1978, e em novembro deste mesmo foram lançados 7.207 metros cúbicos de concreto na obra.

A última etapa e não menos dificultosa que os dirigentes e técnicos da Itaipu deveriam realizar, seria a desapropriação das terras dos agricultores que ocupavam parte da área que 


\title{
OS ROYALTIES DE ITAIPU NA EDUCAÇÃO: UMA ANÁLISE NOS MUNICÍPIOS LINDEIROS NO OESTE DO PARANÁ (1985-2016)
}

seriam atingidas pelo lago de Itaipu. Sendo que cada propriedade era avaliada pelos próprios funcionários da Itaipu de forma arbitrária e injusta:

\begin{abstract}
$\mathrm{Na}$ área necessária para a imponente hidrelétrica viviam aproximadamente 8.000 famílias (cerca de 40.000 mil pessoas) na margem brasileira e 4.000 mil famílias (20.000 mil pessoas) na margem paraguaia. Todas foram forçadas a deixar suas terras, casas e benfeitorias, e lançar-se na luta pela reestruturação de suas vidas, família e comunidades. Os que tinham propriedade foram indenizados, e entre estes houve os que conseguiram fazer bons negócios e também os que se arruinaram. Mas havia muitos que nada possuíam (posseiros, arrendatários, empregados e bóias-frias), e estes, salvo exceções, tiveram de abandonar a área de mãos vazias, lançados à própria sorte (MAZZAROLLO, 2003, p.40).
\end{abstract}

A barragem ficou pronta em outubro de 1982, iniciando-se outra etapa que era resgatar os animais que viviam na área que seria inundada, chegando a serem salvos cerca de 36.450 animais, conforme fontes da Itaipu.

Para Mascarenhas e Castanha (2010) a construção da usina além de trazer impactos sociais também causou grandes impactos ambientais como a perda da vegetação, da fauna, alteração na fauna do rio, migrações de peixes, o desaparecimento do Salto de Sete Quedas, além de perdas históricas, culturais e arqueológicos:

Em 1982, foi aprovado, pela Itaipu Binacional, o Plano de Utilização da Área do Reservatório, onde ficou estabelecida e regulamentada a política da entidade, com respeito a continuidade das providências de caráter ecológico, quanto à implantação dos usos múltiplos que as águas do reservatório proporcionaram: pesca, turismo lazer, abastecimento urbano e industrial, irrigação e outros. (PERIS, 2003, p. 148).

No dia 05 de novembro de 1982, os presidentes do Brasil, João Figueiredo e do Paraguai, Alfredo Stroessner, inauguram oficialmente a maior hidrelétrica do mundo, acionando o mecanismo que levanta automaticamente as 14 comportas do vertedouro, liberando a água represada do Rio Paraná. 


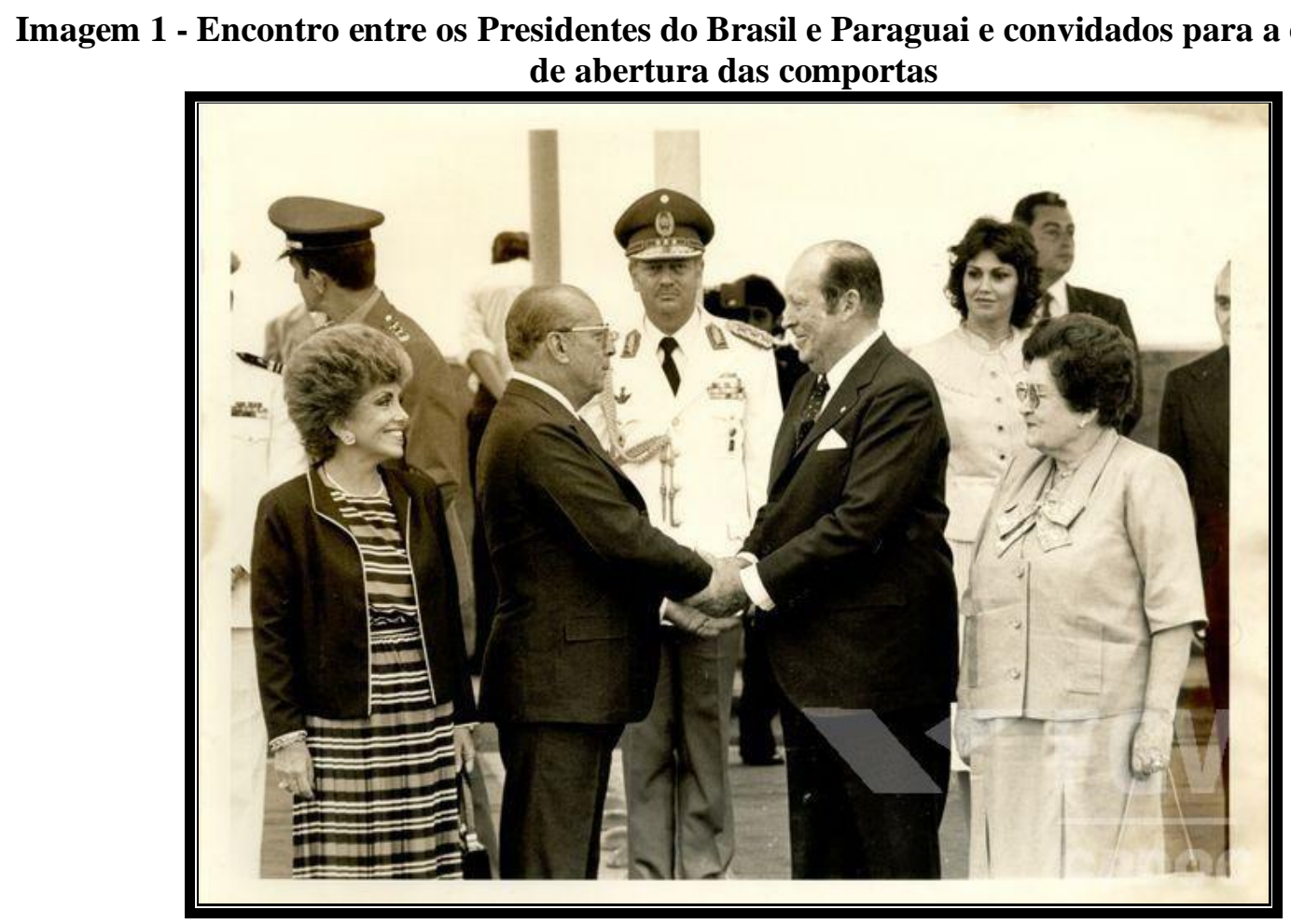

Fonte: Fundação Getúlio Vargas (2018).

O primeiro giro mecânico de uma turbina ocorreu em dezembro de 1983 e em março de 1985 a energia elétrica passa finalmente a ser comercializada. Em 1997, a Itaipu Binacional passa a abastecer $26 \%$ da demanda do setor elétrico do país. No ano 2000 atinge o recorde de produção, gerando 93,4 bilhões de quilowatts-hora. O custo da construção da maior usina hidrelétrica do mundo chega a US\$ 14 bilhões, sendo o valor atualizado em US $\$ 16$ bilhões de dólares, sendo as dívidas com prazo de pagamento até o ano de 2023.

A energia produzida pela gigantesca usina hidrelétrica de Itaipu é enviada para abastecer o sudeste do país, não sendo aproveitado em nenhuma cidade do Paraná, o que causa muita indignação pelos moradores da região lindeira ao lago de Itaipu. 


\section{Imagem 2 - Vista aérea de Itaipu em pleno funcionamento com as três comportas abertas para evasão da água excedente}

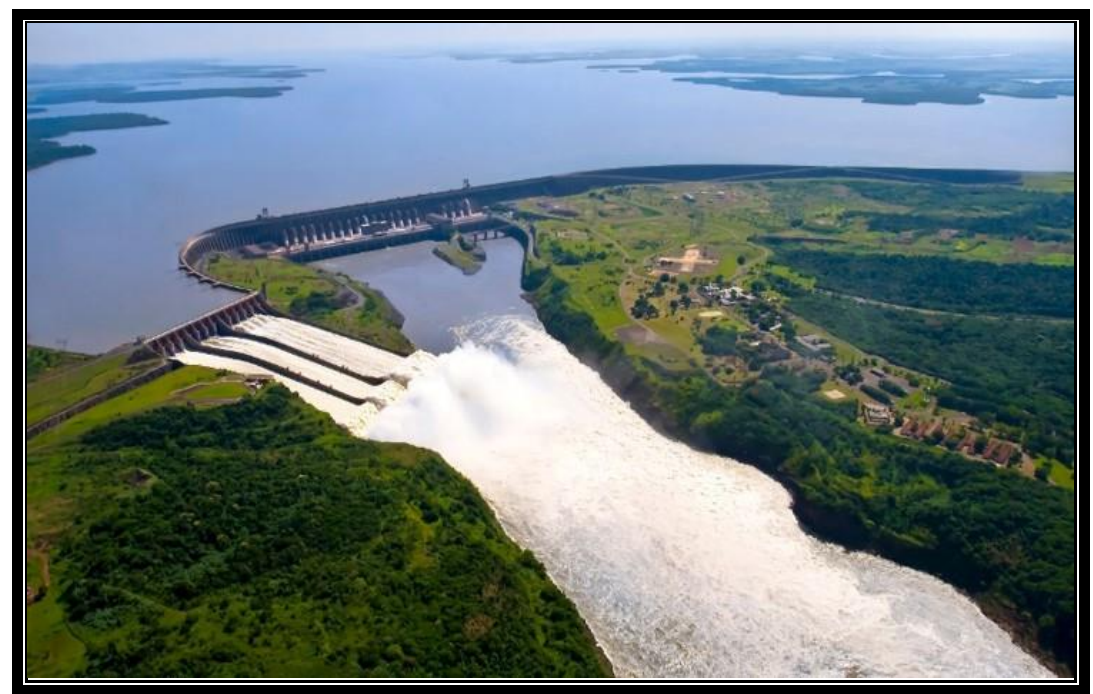

Fonte: Fecomercio.com.br/noticia.

Os municípios de Santa Helena e Itaipulândia, conhecidos no oeste paranaense por serem os recebedores das maiores parcelas de royalties e com alto potencial de investimentos, foram cogitados a se igualarem á países de primeiro mundo, diante das expectativas de desenvolvimento.

Itaipulândia, considerado o terceiro município recebedor das maiores parcelas de royalties de Itaipu, está situado no extremo oeste Paranaense, localizado a uma distância de 630 $\mathrm{km}$ da capital do estado. A população atual de acordo com fontes do IBGE é de 10.413 habitantes, com uma área de aproximadamente $331,288 \mathrm{~km}^{2}$. O Índice de Desenvolvimento Humano em 2010 foi de 0,738 .

Em março de 1992, Itaipulândia tornou-se um município a partir de sua emancipação pela Lei Estadual no 9.908/92. Com a construção da Usina Hidrelétrica de Itaipu, metade de suas terras antes utilizadas com a agricultura foram inundadas pelo lago, causando muitos impactos, entre os quais, o desalojamento de milhares de pessoas em virtude da grande quantidade de terras submersas pela formação do lago de Itaipu.

Scarpato e Böhm (2006) relatam que a Itaipu desapropriou uma área total de 111.332 hectares onde viviam mais de 40.000 brasileiros, causando a migração dessas pessoas para outras regiões como Mato Grosso e Paraguai, também provocou uma movimentação demográfica interna no espaço do Distrito de Aparecidinha do Oeste, onde posteriormente seria 
a sede do Município de Itaipulândia, recebendo muitos moradores. Apontam ainda sobre a inviabilidade econômica:

Logo se percebeu que não haveria sustentabilidade e viabilidade econômica, pois aos poucos a população foi diminuindo. O hospital que havia sido instalado fechou as portas e deixou de atender a população. O mesmo aconteceu com a agência bancária do Bradesco (SCARPATO; BÖHM, 2006, p. 124).

Em 2010, o número de habitantes chegava a 9.000, sendo possível destacar o alto índice de pessoas que se evadiram do município de Itaipulândia. De acordo com informações da secretaria municipal de educação no ano de 2017, o município de Itaipulândia contava com 05 centros municipais de educação infantil, com 420 alunos matriculados; 04 escolas municipais, com 989 alunos matriculados; 01 escola modalidade especial, com 39 alunos matriculados; 02 escolas estaduais de Ensino Fundamental Fase Final com 656 matrículas; 02 Escolas de Ensino Médio, com 298 alunos matriculados e 02 escolas de Educação de Jovens e Adultos com 100 matrículas.

O gráfico a seguir nos ilustra uma melhor percepção dos índices alcançados pelo município nos anos de 2007, 2009, 2011, 2013, 2015 e 2017.

\section{Gráfico 1 - Nota do IDEB Municipal}

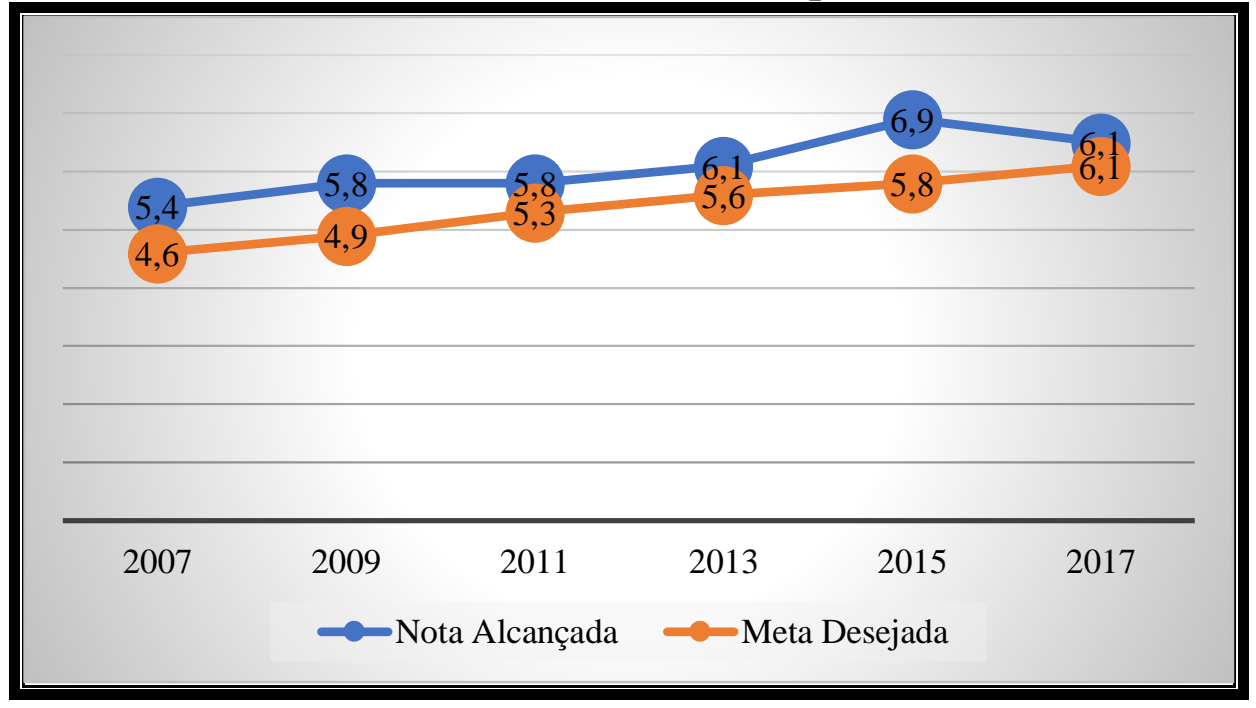

Fonte: Elaborado pelos autores.

O gráfico nos possibilita uma visualização da elevação conquistada em 2015 e sua decaída no ano de 2017. De acordo com o IPARDES, a taxa de analfabetismo verificada por meio do último Censo, realizado em 2010, constatou que existe um percentual de 7,69\% de analfabetos com 15 anos ou mais, que declararam não estarem aptos a ler e a escrever. O IBGE 
identificou, no mesmo ano, por meio do censo, que a taxa de escolarização de 06 a 14 anos abrangeu $99,2 \%$ da população

A taxa de rendimento escolar nos Ensino Fundamental e Médio, de acordo com a fonte do IPARDES no ano de 2017, revela que o índice de aprovação no Ensino Fundamental (Anos iniciais $-1^{\circ}$ ao $5^{\circ}$ ano) é de $91,3 \%$ dos alunos; a taxa de reprovação é de $7,9 \%$ e $0,8 \%$ de abandono. No Ensino Fundamental (Anos finais $-6^{\circ}$ ao $9^{\circ}$ ano), possui uma aprovação de $73,5 \% ; 26,2 \%$ de reprovação e 0,3\% de abandono. O Ensino Médio apresenta que 59,3\% dos seus alunos foram aprovados; $37,9 \%$ foram reprovados e 2,8\% abandonaram a escola.

Ao analisarmos os resultados, identificamos que a taxa de abandono escolar é pequena, no entanto, o índice de reprovação possui um número elevado, indicando a necessidade de repensar uma forma para reduzir esses números. Outra observação que podemos identificar está relacionada à taxa de abandono escolar entre o Ensino Fundamental Fase Inicial e Final, em que a taxa de abandono foi maior no Ensino Fundamental Fase Inicial, sendo normalmente constatado o contrário.

De acordo com a Secretaria de Estado do Paraná, em 2010 o município de Itaipulândia recebeu a Declaração de Território Livre do Analfabetismo por meio do Programa Paraná Alfabetizado. O programa é desenvolvido em parceria com as prefeituras, organizações da sociedade civil e universidades estaduais.

O município de Itaipulândia já foi beneficiado com os royalties de Itaipu entre os anos de 1997 a 2017. Isso fez com que o município de Itaipulândia se tornasse o município com maior investimento per capita como explica Toillier apud Balzan (2014):

Segundo estudos da Fundação Getúlio Vargas de 2007, Itaipulândia foi o município brasileiro com maior investimento per capita em saneamento básico e saúde no ano de 2000; em 2007 foi o município que mais investiu em educação no Paraná, com o investimento de 106,39\% da sua arrecadação de impostos, quando o mínimo exigido por lei é de $25 \%$, ou seja, todo o valor arrecadado pelo município, além de uma parte dos royalties; segundo o levantamento do Departamento de Economia Rural do Estado do Paraná (DERAL) é o $26^{\circ}$ município do Paraná em destaque no agronegócio, algo digno de reconhecimento, uma vez que o município é pequeno se comparado com outros, além de investir nas áreas de desenvolvimento rural sustentável e cuidado com matas ciliares; e finalmente, com uma parceria com a Itaipu Binacional, reduziu a zero os passivos ambientais de suas microbacias hidrográficas, sendo o primeiro município da Bacia do Paraná III que abrange a região Oeste do Paraná (TOILLIER apud BALZAN, 2014, p. 39). 
Podemos verificar que o município realizou grandes investimentos no que diz respeito a educação aplicando $81,39 \%$ a mais que o exigido por lei. Os maiores investimentos foram destinados à educação infantil, sendo construídas instituições e contratado profissionais para atender e assegurar o direito da criança em frequentar a educação infantil, extinguindo praticamente a lista de espera por vagas.

\section{Gráfico 2 - Royalties recebidos pelo Município de Itaipulândia e a aplicabilidade na educação}

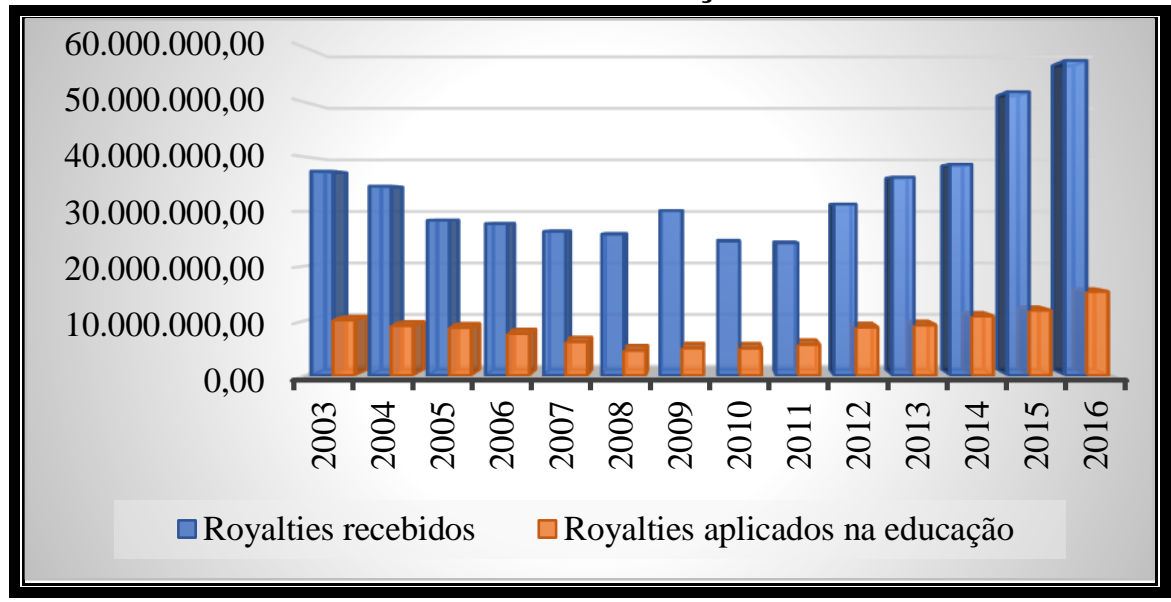

Fonte: Elaborado pelos autores.

Outra área que demandou altos investimentos, diz respeito ao ensino técnico em nível médio e ensino superior, onde o município contratou empresas para prestarem serviços de transporte de alunos para outros municípios, além do fornecimento de subsídios de estudo, no qual o aluno pode receber um auxílio financeiro no valor de $\mathrm{R} \$ 500,00$ à $\mathrm{R} \$ 600,00$ mensais para custeio das mensalidades de instituições privadas.

\section{Gráfico 3 - Arrecadação em royalties e receita livre no ano de 2017}

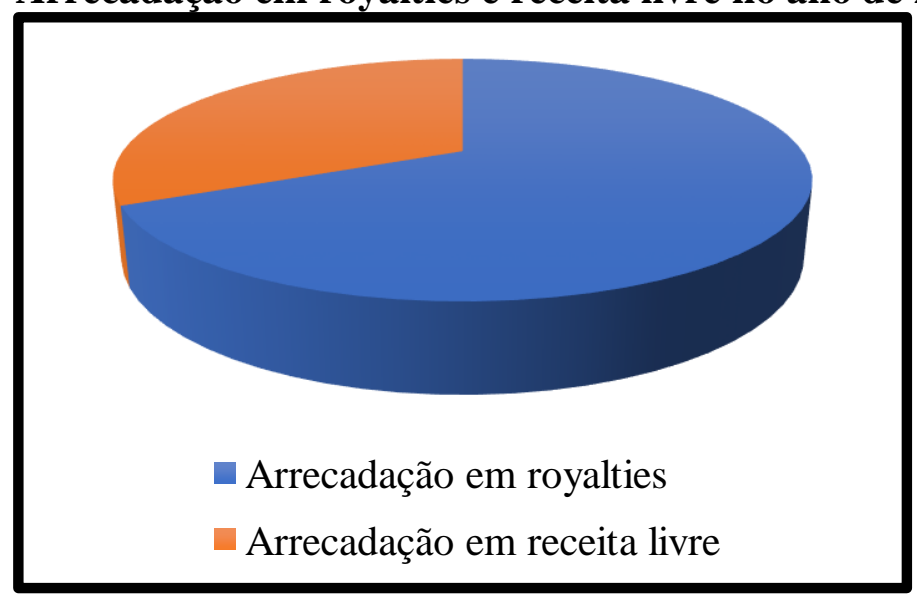

Fonte: Elaborado pelos autores. 
O Município de Santa Helena encontra-se aproximadamente a $620 \mathrm{Km}$ da capital do estado - Curitiba, no Centro da Costa Oeste do Paraná, conhecida também como "Terra das Águas" por ter grande parte de suas terras alagadas pelo lago de Itaipu, onde ficou praticamente ilhada. De acordo com dados do IBGE (2016) a população está estimada em 25.665 habitantes, possuindo uma área territorial aproximadamente em $758,23 \mathrm{~km}^{2}$.

Após a emancipação política em 1967, foram criadas as primeiras escolas municipais rurais que ficaram sobre responsabilidade do município pela manutenção do prédio escolar e o pagamento dos professores. Com a formação do lago de Itaipu, Santa Helena sofreu grande impacto socioeconômico, onde milhares de pessoas foram obrigadas a saírem de suas terras, abandonando assim, anos de trabalho e conquistas, para um futuro incerto. A redução populacional, ocasionou uma depressão no comercio, fazendo com que muitos comerciantes fechassem suas portas. Muitas escolas foram fechadas por falta de alunos, conforme corrobora Sterchile (2006).

\section{Imagem 3 - Vista aérea da cidade de Santa Helena e o lago de Itaipu}

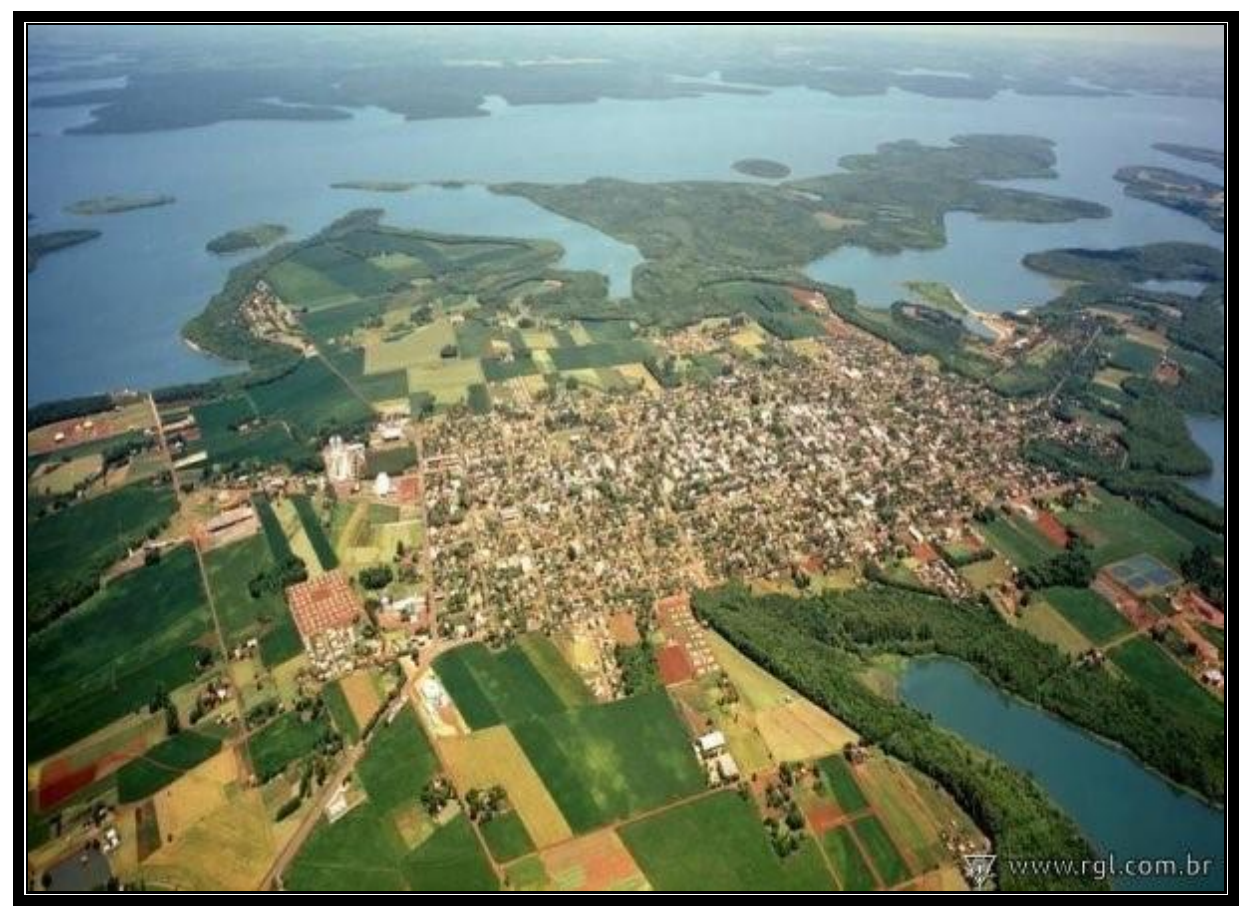

Fonte: Acervo pessoal de Koch (2006).

Segundo Sterchile (2006) em 1980 o município contava com 67 escolas, e com o alagamento muitos moradores migraram para outras regiões, sendo que em 1985 dezessete escolas foram fechadas. Restaram-se então 49 escolas rurais municipais e 9 dessas escolas 
passaram a pertencer ao município de São José das Palmeiras a partir de sua emancipação em 1985.

Desta forma evidenciamos, que os principais motivos pela evasão da população no município de Santa Helena, se deu principalmente pela formação do reservatório do lago de Itaipu, posteriormente pela emancipação do município de São José das Palmeiras e pela mecanização agrícola, fazendo com que muitas pessoas fossem em busca de novos campos de trabalho em outras cidades.

A seguir poderemos observar através da tabela as variações populacionais no município de Santa Helena entre os anos de 1970 a 2010.

Tabela 2 - Índice populacional no município de Santa Helena nos anos de 1970, 1980, 1991, 2000 e 2010

\begin{tabular}{|l|l|l|l|l|l|}
\hline Ano/Censo & $\mathbf{1 9 7 0}$ & $\mathbf{1 9 8 0}$ & $\mathbf{1 9 9 1}$ & $\mathbf{2 0 0 0}$ & $\mathbf{2 0 1 0}$ \\
\hline População & 26.834 & 34.882 & 18.861 & 20.491 & 23.413 \\
\hline
\end{tabular}

Fonte: Prefeitura Municipal de Santa Helena (2015).

Estudos sobre o esvaziamento escolar no município de Santa Helena a partir do projeto Itaipu, constatando um significativo processo de evasão escolar naquele período, sendo que várias escolas foram fechadas devido a indenização e outras por falta de alunos.

[...] vemos [...] que o município de Santa Helena, no decorrer dos anos de 1971 a 1986, teve 106 escolas de $1^{\mathrm{a}}$ a $4^{\mathrm{a}}$ séries das quais, 10 passaram a pertencer ao Município de São José das Palmeias, 28 foram desapropriadas pela Itaipu Binacional, 26 foram extintas por faltas de alunos, restando em Santa Helena apenas 43 escolas (MARTINS apud FOCHEZATTO, 2012, p. 115).

O município de Santa Helena, no ano de 2017, contava com 07 Centros de Educação Infantil com 562 alunos matriculados, 10 Escolas da rede Municipal com 2.325 alunos matriculados, 08 Escolas Estaduais Ensino Fundamental Fase Final com 1.200 alunos matriculados, 04 Escolas Estaduais - modalidade Ensino Médio com 757 matrículas efetivadas, 02 Escolas de Educação de Jovens e Adultos com 246 matrículas, 06 escolas de Educação Especial com 53 matrículas efetivadas e por fim, 01 Universidade Federal, Universidade Tecnológica Federal do Paraná (UTFP) que iniciou suas atividades, nas antigas instalações da 
Universidade do Oeste do Paraná (UNIOESTE), ofertando 02 cursos: Bacharelado em Ciência da Computação e Licenciatura em Ciências Biológicas.

Imagem 4 - Vista aérea das instalações da Universidade do Oeste do Paraná - Unioeste - Extensão Santa Helena

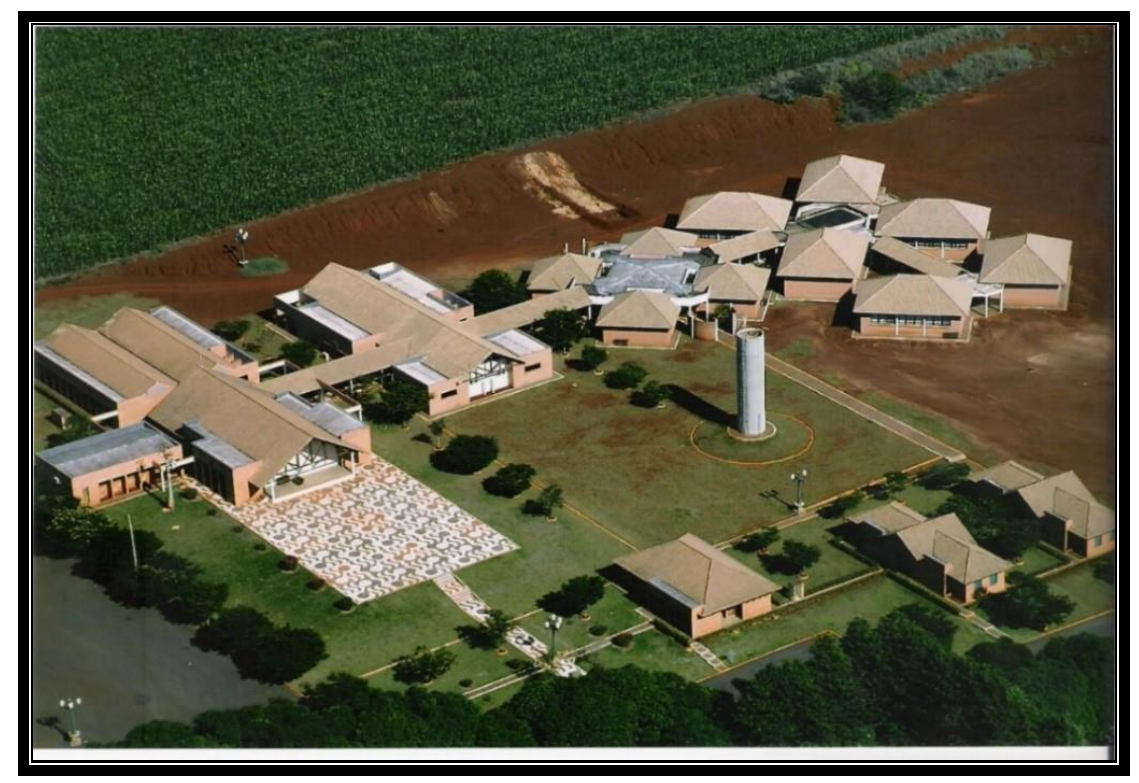

Fonte: Acervo pessoal de Koch (2002).

Em relação aos royalties, o município de Santa Helena foi o mais beneficiado, sendo depositado aos cofres públicos mais $\mathrm{R} \$ 910.000 .000,00$ (novecentos e dez milhões de reais) desde o ano de 1997 até 2017 conforme relatório publicado pela Aneel.

\section{Gráfico 4. Arrecadação em royalties e receita livre no ano de 2017}

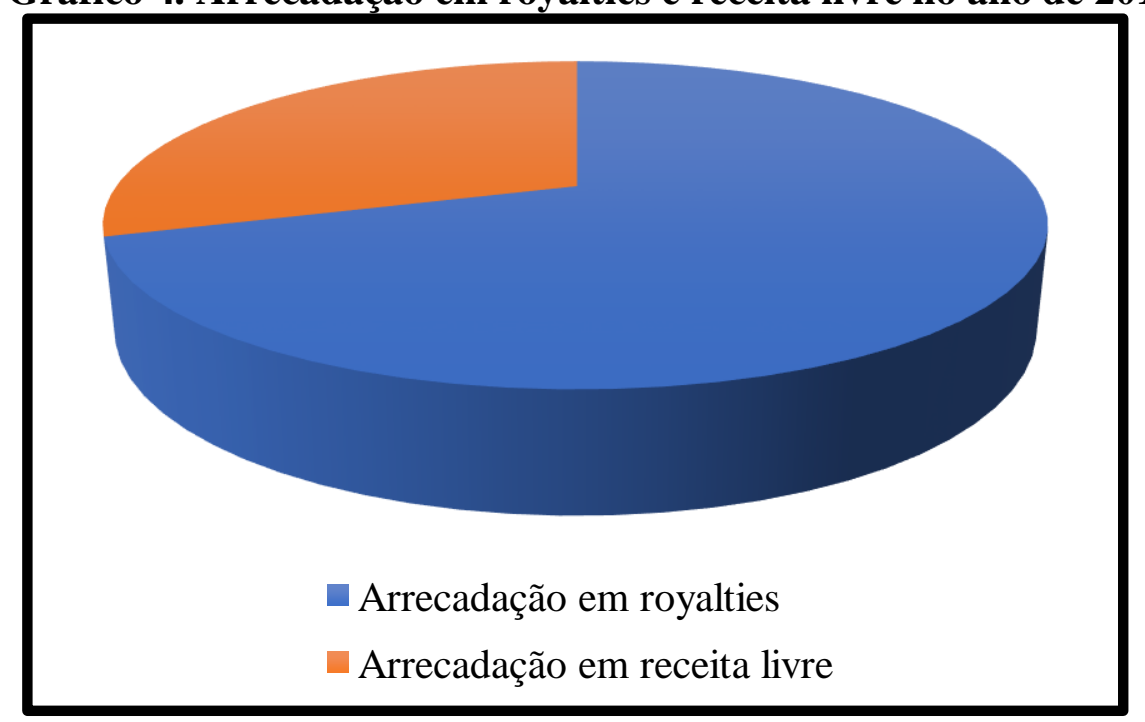

Fonte: Elaborado pela autora. 
Santa Helena também teve seus principais investimentos voltados para a educação infantil e o ensino superior. Nos últimos anos foram construídos espaços para a destinação ao atendimento à educação infantil, além da contratação de mais de 90 professores de educação infantil, através de concurso público, além da contratação de 100 bolsas de estudo de uma escola privada. Hoje o município ainda possui uma pequena lista de espera de crianças que aguardam serem chamados para frequentar a educação infantil.

Verificamos que o município, entre o período de 2003 a 2016, investiu cerca de 16\% dos royalties, restando ainda $84 \%$ do recurso para aplicar nas demais áreas (aproximadamente 7,63\% para cada uma). O gráfico a seguir nos indica uma dimensão dos royalties recebidos e dos royalties aplicados na educação no município de Santa Helena entre os anos de 2003 e 2016:

Gráfico 5 - Royalties recebidos pelo Município de Santa Helena e a aplicabilidade na educação

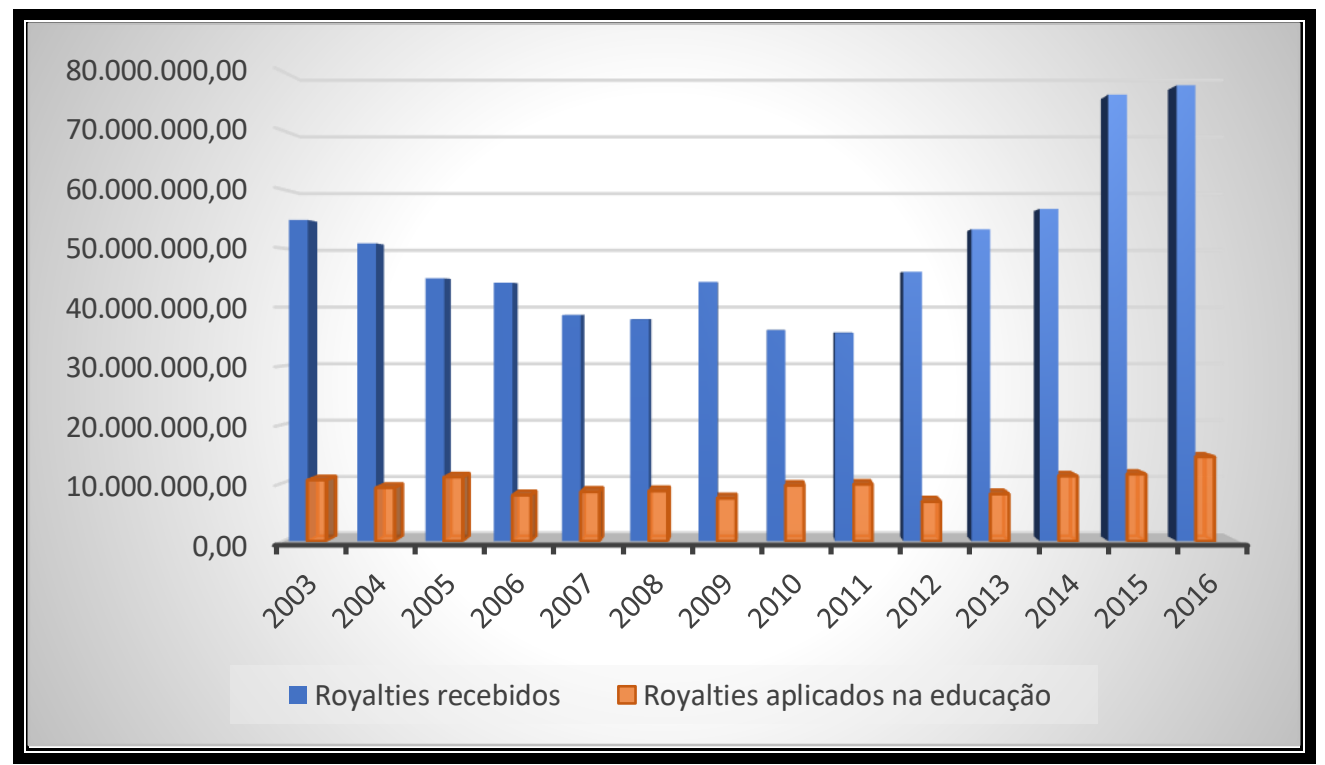

Fonte: Elaborado pelos autores

No que se refere aos investimentos no ensino superior, os alunos conquistaram o direito de receber $70 \%$ do valor pago ao transporte intermunicipal, além do município ter investido na construção de uma estrutura que foi cedida inicialmente para atender a UNIOESTE e que hoje foi doada para atender a UTFP, que oferta 03 cursos (Agronomia, Ciências Biológicas, Ciências da Computação).

A educação básica, na modalidade Ensino Fundamental - fase inicial, também recebeu investimentos, como reformas e construção de escolas, reforma e construção de Ginásios de 
Esportes, os quais são utilizados para aulas de educação física, entre outras melhorias que proporcionaram qualitativamente na educação do município.

\section{CONSIDERAÇÕES FINAIS}

Em face dos apontamentos, podemos considerar que Itaipu, por um lado, solucionou parte do problema da crise energética demandada pelo setor das indústrias brasileiras, por outro, causou grandes impactos nas áreas atingidas pelo reservatório, fazendo com que uma grande parcela da população que viviam nesta área fosse retirada, diminuindo consideravelmente a população dos municípios, além de deixar submersas grandes áreas produtivas, das quais os agricultores levaram anos para deixar férteis.

Itaipu foi um projeto do Governo Civil-Militar (1964-1985), para atender as exigências da indústria, de acordo com as demandas da expansão capitalista. Por outro lado, mas sob um olhar dos atingidos pelo lago, as pequenas cidades do extremo Oeste Paranaense sofreram grandes impactos em seus planejamentos.

A construção da imponente usina hidrelétrica de Itaipu trouxe diversos impactos para a região oeste paranaense, tanto no que diz respeito a fatores econômicos, quanto sociais. Os municípios de Santa Helena e Itaipulândia tiveram importantes prejuízos no que se refere às perdas territoriais, onde um grande número de pessoas teve que deixar seus lares em busca de novas oportunidades de vida em outras cidades e estados. A economia estagnou, os comércios ficaram vazios e ainda, grande parte das terras antes produtivas ficaram submersas as águas do lago de Itaipu, deixando de produzir milhares de toneladas de milho e soja por ano.

Na questão social, a população também foi prejudicada, pois famílias, vizinhos, comunidades foram desfeitos em prol da Itaipu, o suor e o desgaste físico daqueles que desbravaram matas fechadas para transformar em moradias, plantações e pequenas comunidades, viram seus sonhos destruídos. Escolas foram desapropriadas e muitas outras fechadas devido à falta de alunos.

A compensação financeira paga através dos royalties pela Itaipu a estes municípios, é considerada de extrema importância, pois a partir desse montante é que os municípios puderam se reerguer e superar alguns traumas produzidos pela construção da hidrelétrica. Podemos considerar também, com o pagamento dos royalties, foram possíveis inúmeros investimentos que foram destinados à educação, saúde e infraestrutura, reformas em escolas, ginásios de esportes, construção de salas de aula, construções de centros municipais de educação infantil, 
e prédio para instalação de uma universidade, que por seis anos abrigou o Campus avançado da UNIOESTE.

Os recursos investidos para a implantação de uma universidade pública, apesar dos avanços e recuos, foi uma importante conquista cultural e educacional para a região. Atualmente, a abertura do Campus da Universidade Tecnológica Federal do Paraná - UTFPR trouxe a possibilidade de estudo em uma instituição pública e de qualidade sem precisar sair do município.

A Itaipu que inicialmente trouxe sérios prejuízos para os municípios lindeiros ao lago, ao longo do tempo, a compensação financeira, acarretou significativos investimentos realizados pelos gestores. Sem os royalties, os municípios estariam vivendo à míngua, com baixos recursos a serem aplicados. O potencial turístico da região próximo ao lago também foi uma frente importante de desenvolvimento, criando perspectivas até então não conhecidas ou vislumbradas.

Os municípios aqui analisados tornaram-se dependentes das transferências dos royalties, na manutenção do setor educacional, e que, sem esses valores, poucos investimentos seriam possíveis. Os royalties tornaram-se um enorme potencial na melhoria das condições de via da população lindeira, como a erradicação da pobreza, investimento da saúde e outros serviços básicos, além de evitar a degradação do meio ambiente. Por outro lado, há a necessidade de maiores benefícios sociais, especialmente no campo educacional, em relação ao montante de recursos recebidos.

Existe a necessidade de elaborar alternativas visando à sustentabilidade econômica desses municípios, conquistando progressivamente a independência desses recursos considerados como extras. Esta situação precisa ser urgentemente estudada para não sofrer com o impacto com o possível corte desse repasse.

Grosso modo, os resultados apresentados sugerem que, apesar das vantagens dos recursos provenientes do Royalties, sua aplicabilidade nos municípios, não tem produzido a tão desejada justiça social por meio de acesso igualitário aos sistemas de saúde, habitação e, particularmente, de educação, diante das expectativas geradas.

Ao receberem royalties, os municípios aumentaram significativamente os seus orçamentos. Porém, o desafio estava na transformação dos gastos em desenvolvimento qualitativo da educação e, por consequência, refletir em melhoria da qualidade da população. 
Entendemos que este estudo não é conclusivo, é o primeiro estudo sobre as aplicações efetivadas no campo educacional dos municípios.

Neste sentido, indicamos a necessidade de outras pesquisas no sentido de aprofundar estudos acerca dos aspectos qualitativos no que tange à educação em razão da aplicabilidade dos royalties, e seus efeitos na melhoria da qualidade das escolas públicas na região. Por fim, esperamos, com estes apontamentos, contribuir para uma análise dos investimentos nas escolas públicas nos municípios lindeiros, a partir dos investimentos resultantes dos royalties da usina de Itaipu. Desse modo, é necessário avançar na investigação.

\section{REFERÊNCIAS}

BALZAN, Celso Sidinei. Os desafios da implantação e implementação da pedagogia histórico crítica nos anos iniciais do ensino fundamental em Itaipulândia. 2014. 163 f. Dissertação (Mestrado em Sociedade, Estado e Educação) - Universidade Estadual do Oeste do Parana, Cascavel, 2014.

BRASIL. Constituição da República Federativa do Brasil. Brasília: Senado Federal, 1988.

BRASIL. Agencia Nacional de Energia Elétrica. Aneel. Disponível em: http://www2.aneel. gov.br>. Acesso: 15/02/2018

BRASIL. Lei $\mathbf{n}^{\mathbf{0}}$ 13.661, de 08 de maio de 2018. Altera a Lei $\mathrm{n}^{\circ}$ 8.001, de 13 de março de 1990, para definir as parcelas pertencentes aos Estados e aos Municípios do produto da Compensação Financeira pela Utilização de Recursos Hídricos (CFURH). Diário Oficial da União, Brasília, DF, 09 maio 2018. S. 1.

BALZAN, C. S. Os desafios da implantação e implementação da pedagogia históricocrítica nos anos iniciais do ensino fundamental em Itaipulândia. Cascavel, 2014. (Dissertação de Mestrado). UNOESTE, Campus Cascavel.

COLODEL, J. A. Obras e Companhias Colonizadoras. Cascavel: Assoeste, 1988.

. História de Santa Helena: descobrindo e aprendendo: ensino fundamental. Santa Helena: Prefeitura Municipal, Secretaria de Educação e Cultura, 2000.

FOCHEZATTO, A.; KUIAVA, J. Reflexos de um Regime Tecnocrático/Autoritário: Influência do Projeto Itaipu no Contexto Escolar do Município de Santa Helena. In._SILVA, João Carlos da Silva; CASTANHA, André Paulo; ORSO, Paulino José ZANOTTO, Marijane. História da Educação: escola pública e práticas educativas. Cascavel: Edunioeste, 2012. 
MASCARENHAS, M. C.; CASTANHA, A. P. A Construção da Itaipu e os Reflexos na Educação de Foz do Iguaçu. In: CASTANHA, A. P. et al. (Orgs.). História da

Educação; Levantamentos de Fontes e Instituições Escolares. Cascavel: Edunioeste, 2010.

MAZZAROLLO, J. A Taipa da Injustiça. $2^{\text {a }}$ ed. São Paulo. Edições Loyola.

PERIS, A. F. Estratégias de Desenvolvimento Regional: Região Oeste do Paraná. Vários autores. - Cascavel: Edunioeste, 2003.

PERIS, A. F. Estratégias de Desenvolvimento Regional: Região Oeste do Paraná. Cascavel: Edunioeste, 2003.

SBARDElotTO, D. K. CORREA, J. J. História da Criação do Colégio Bartolomeu Mitre, o Primeiro Grupo Escolar do Oeste do Paraná: Contexto Histórico (1889 a 1930). In._CASTANHA, André Paulo; ORSO, Paulino José; SILVA, João Carlos da; BATISTA, Marco Antônio. História da Educação; Levantamentos de Fontes e Instituições Escolares. Org. Carvalho. Cascavel: Edunioeste, 2010.

SCARPATO, R.; BÖHM, I. História de Itaipulândia. $1^{\text {a }}$ edição. Cascavel, PR: Assoeste Ltda, 2006.

STERCHILE, Adriela. Aspectos da História das Instituições Escolares de Santa Helena. 2006. 39 f. Trabalho. Especialização em História da Educação Brasileira) - Universidade do Oeste do Paraná, UNIOESTE. Cascavel, Paraná.

THIBES, Juliana Schwaab. Itaipu: a pedra que canta e desencanta: uma análise dos royalties na educação nos municípios de Santa Helena e Itaipulândia (2003-2016). 2019. 230 f. Dissertação. (Mestre em Educação) - Universidade Esadual do Oeste do Paraná, Cascavel, 2019.

TOILLIER, Jean Sebastian. A formação do professor (de matemática) em terras paranaenses inundadas. 2013. 285 f. Dissertação (mestrado) - Universidade Estadual Paulista, Instituto de Geociências e Ciências Exatas, 2013. Disponível em:

<http://hdl.handle.net/11449/91144>. Acesso em 10/03/2021

XAVIER, M. E.; RIBEIRO, M. L.; NORONHA, O. M. História da Educação: a escola no Brasil. São Paulo: FTD, 1994.

\section{NOTAS}

\footnotetext{
i Em meados de 1973, a crise do petróleo vai manifestar-se quando os países árabes membros da Opep (Organização dos países Exportadores de Petróleo) decidem suspender as exportações, em sinal de protesto ao apoio dado a Israel por países do Ocidente no conflito com o Oriente Médio. Essa ação leva ao encarecimento do produto prejudicando países como o Brasil que dependiam em grande parte do petróleo importado [...] (XAVIER, 1994. p. 261).
} 